\title{
Opportunities of Artificial Intelligence and Machine Learning in the Food Industry
}

\author{
Indrajeet Kumar $\mathbb{D}^{1},{ }^{1}$ Jyoti Rawat $\mathbb{D}^{2},{ }^{2}$ Noor Mohd $\mathbb{D},{ }^{3}$ and Shahnawaz Husain $\mathbb{D D}^{4}$ \\ ${ }^{1}$ Graphic Era Hill University, Dehradun, Uttarakhand, India \\ ${ }^{2}$ DIT University, Dehradun, Uttarakhand, India \\ ${ }^{3}$ Graphic Era Deemed to be University, Dehradun, Uttarakhand, India \\ ${ }^{4}$ College of Engineering \& Technology, Samara University, Semera, Ethiopia \\ Correspondence should be addressed to Shahnawaz Husain; shahanawazhusain@su.edu.et
}

Received 11 June 2021; Revised 30 June 2021; Accepted 6 July 2021; Published 12 July 2021

Academic Editor: Rijwan Khan

Copyright $\odot 2021$ Indrajeet Kumar et al. This is an open access article distributed under the Creative Commons Attribution License, which permits unrestricted use, distribution, and reproduction in any medium, provided the original work is properly cited.

\begin{abstract}
The food processing and handling industry is the most significant business among the various manufacturing industries in the entire world that subsidize the highest employability. The human workforce plays an essential role in the smooth execution of the production and packaging of food products. Due to the involvement of humans, the food industries are failing to maintain the demand-supply chain and also lacking in food safety. To overcome these issues of food industries, industrial automation is the best possible solution. Automation is completely based on artificial intelligence (AI) or machine learning (ML) or deep learning (DL) algorithms. By using the AI-based system, food production and delivery processes can be efficiently handled and also enhance the operational competence. This article is going to explain the AI applications in the food industry which recommends a huge amount of capital saving with maximizing resource utilization by reducing human error. Artificial intelligence with data science can improve the quality of restaurants, cafes, online delivery food chains, hotels, and food outlets by increasing production utilizing different fitting algorithms for sales prediction. AI could significantly improve packaging, increasing shelf life, a combination of the menu by using AI algorithms, and food safety by making a more transparent supply chain management system. With the help of AI and ML, the future of food industries is completely based on smart farming, robotic farming, and drones.
\end{abstract}

\section{Introduction}

It is well known that food or ration is a necessary for human beings and can be described as the best outcome of farming, fashioned after handing out the various foodstuffs shaped by farmers. For any country's development, the food industry's products play a crucial role [1]. It also has a significant role in the development of the country's economy as well as the world economy. Therefore, the quality of food industry products and their safety with proper distributions are much needed. In the last few decades, newly developed technology such as artificial intelligence (AI) achieved good results to attain the desired objectives [2]. Therefore, it is essential to investigate the AI-based smart agriculture and advanced food industry aspects. Such techniques fulfill social requirements and deliver quality products on time. By using these modern technologies, the food industry can produce a large number of food products in less time that will increase the economy of the company in exponential manner [2].

AI-based systems or autonomous systems are extensively applied in approximately every portion of the technology. It enables the world to efficiently optimize the problems, computerize the food industry, and transfigure food industries products [3]. By using a computerized system, the industry can examine and make sure the most favourable circumstances such as seed selection, crop monitoring, watering, and temperature monitoring can be improved, which will provide excellence of the food industry products 
$[4,5]$. The use of AI is not limited to these things only. It can also be helpful in food processing, storage, and delivery of food items. Intelligent gadgets such as robotics and intelligent drones can also play a very crucial and significant role in minimizing the packaging cost. It will also help in delivering the food products, completing the task in perilous surroundings, and also providing very-good-quality products [6-8]. The important roles of AI in food industries can be broadly classified into two classes: one is food security management, and another one is food quality management. The area under each class is given in Figure 1. By keeping every aspect of $\mathrm{AI}$ in the food industry, this study provides a literature study of machine learning and AI in the food industry.

The rest of the manuscript is organized as smart farming followed by AI in the food processing industry. After this, the role of data analysis in the food industry is discussed; then, ML in the restaurant business is discussed. As per the food safety concern, $\mathrm{AI}$ is also important; therefore, the next section will describe the $\mathrm{AI}$ in food safety. At last, but not the least, the future scope of $\mathrm{AI}$ and $\mathrm{ML}$ in the food industry is covered. Finally, the conclusion of the manuscript is included in the last section.

\section{Smart Farming}

In the food industry, AI also has some important applications such as soil monitoring, robocroping, and predictive analysis [9-11]. Figure 2 shows the trendy applications of AI in the food industry. The description of each application is given in the forthcoming section.

2.1. Soil Monitoring. In the current scenario, food industries are considering the benefits of AI-based systems. Under the AI-based system, computer vision and deep-learning algorithm is very important and used to investigate the sequence of information or data received by the AI-based agents to trace the progress of crop and soil health [10, 12-22]. The computerized systems are used to make available clients with a sagacity of their soil's strengths and weaknesses. The prime objective behind the building of the developed system is to identify defective crops and identify the probable approach for healthy crop development.

In the recent scenario for Soil Monitoring (SM), once a farmer submits a sample of their farm soil to the monitoring body, afterwards, the customer will get a detailed summary of their field soil contents. After the drawn results, an adequate decision has been taken for bacteria, fungi, and wideranging microbial progression.

The first AI-based drone was used in Japan in the year 1980 for crop dusting. Today, most companies are taking advantage of agriculture AI and aerial technology to keep an eye on crop health [15]. The company's primary endeavour is to decrease the costs and improve crop growth. Users preprogram the drone's route and then will integrate with the device. After that, the computer vision will record some pictures that will be used for examination purposes.

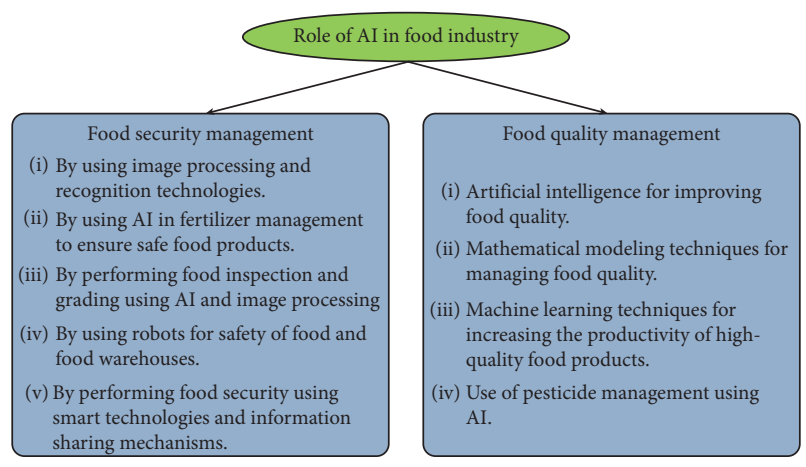

FIgure 1: Role of AI in food industry.

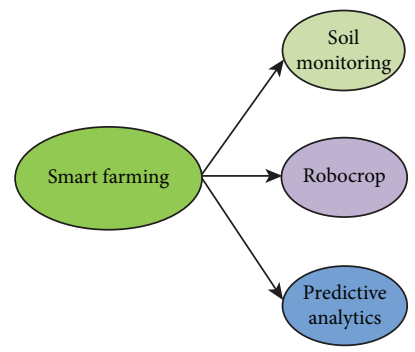

FIgURE 2: Smart farming.

Now, further technology moved to the new era of advancement is called the Internet of Things (IoT). The IoT plays an important role in decision on crop and soil monitoring [16]. SM with IoT is the application of AI that supports farmers and food industries to capitalize on their economy, diminish the chances of ailment, and optimize uses of available assets. In these, sensors are deployed to sense the temperature of the soil, amount of nitrogen, phosphorus, and potassium (NPK) in soil, moisture level, the content of water, potential in soil, amount of photosynthetic radiation, and oxygen level in soil [17]. The collected data from the various sensors are again forwarded to the data centre point or the cloud for a proper decision so that adequate action can be taken timely. The outcome of the analysis, visualization of received data, is helpful in resource utilization. The identification of the behaviour of the system requires identifying the trends of soil and making the delicate decision to circumstances to get maximum crop yield and excellent products $[16,17]$. The agriculture-based IoT is called smart agriculture. The IoT-based food industry is called the smart food industry.

IoT-based agriculture is completely based on soil monitoring, weather forecasting, and crop monitoring. As it is known, weather and irrigation play a very crucial role in IoT-based agriculture. The smart agriculture elucidations are also attached with an elegant atmosphere such as good air quality and a well-groomed watering system. The commonly applicable sensors and types of measures considered by the respective sensors are given in Table 1.

In the literature, so many studies [13-20] were found on smart farming and noticed that by using these modern tools, resources can be utilized in an optimized manner and the income can be maximized. Also, there are some specific 
TABle 1: Sensors and types of measures considered by the respective sensors.

\begin{tabular}{lcc}
\hline Sr. no. & Type of sensor & Measurement \\
\hline 1 & Temperature sensor & Soil temperature \\
& & Noncontact shell temperature \\
\hline & Moisture sensor & Soil wetness \\
& & Conductivity \\
& & Wolumetric water content \\
& Solar radiation & Active radiation \\
3 & & UV radiation \\
& & Solar-shortwave \\
\hline & & Rainfall \\
& & Warmth \\
4 & Weather & Moisture \\
& & Air pressure \\
& & Speed of wind \\
& & Flow direction of wind \\
\hline & & Nitrogen level \\
& & Phosphorous level \\
& & Potassium level \\
& & pH level \\
& & Temperature level \\
& & Moisture level \\
\hline
\end{tabular}

areas such as cannabis and hemp, soybeans, potato, almonds, cherries, apples, and grapes yielding promising production by using smart farming.

2.2. Robocrop. With the advancement in technology, the food industry is also using modern-technology-based tools so that production can be increased. One of the tools developed by the various research groups is called robocrop [18]. It is an AIbased robotic system that advances the yielding process by maximizing usefulness and uniformity. It conducts line up crop tools accurately and at a high rate. The food industry product shrubbery forward of the system is monitored by a high-resolution and precise system. The captured image is processed by a high-performing workstation to attend the maximum attentiveness of green band pixels relating to the crop line. Due to the outsized region captured by the input devices and the numerous processing line, an outstanding typical crop centre-line tracking is accomplished [19]. It evaluates the resultant image to a ground truth gridiron pattern with the crop line area. The obtained information is then employed to align the instruments in the row via a hydraulic-based shift. The pattern-based attribute builds the system very healthy besides backdrop pick over infestations. It improves the performance and production rate just because of multicameras and multiple sensors.

In robocroping or agricultural automation, outstanding work has been carried out by various authors in the field of harvesting robots [23-25] that has increased productivity considerably in recent decades. These systems became popular due to advancement and additional benefits which are improved productivity and reduced labor force. The previously published article [23] described the dual-arm harvesting robot which consists of dual arms arranged in an optimized manner. This dual-arm robot is suitable for fruit harvesting and based on SVM. In agricultural automation, robotic weeding facilitates weed control near or within crop rows automatically and effectively. An image-processingbased system [24] was designed for identifying crop plants at various growth levels for robotic weeding control. In the list of existing systems, a specific system was developed for strawberry flowers known as Adaptive Robotic Chassis (ARC) [25]. In that system, strawberry flowers are captured by the installed camera and then processed. Finally, the desired coordinate has been obtained and the significant actions are taken by the robot.

The performance of the robocrop completely depends on input image features. If the input image contains more dominant features, then it shows outstanding results. In every sample of an input image, the crop must present more shrubbery than the wildflower and the crop shrubbery should be near to the mean of the RGB colour band. A typical robocrop system consists of a robocrop console part, a hydraulic-based shaft, a three-point linkage frame, a highdefinition camera, various types of speed sensors, an ADC adapter, and so on. Figure 3 shows one sample of robocrop picking fruits [19].

2.3. Predictive Analytics. Learning models are developed to trail and forecast various environmental effects on crop yield such as weather changes. For this, ML algorithms account for a very significant role. ML algorithms in association with the satellites investigate crop sustainability, predict the weather, and assess farms to know about the existence of pests and diseases. The model is very good at delivering highstandard data or information that is perpetually updated at a quick rate. Also, the organization is very much confident about the data it provides for its customers with admittance to more than one billion stacks of agronomic data regularly. The data sources such as precipitation, wind speed, solar radiation, and temperature along with historical values are important for predictive analysis. The obtained analysis accounts an important role for adequate scheduling and crop selection for particular agricultural land [20].

FarmShots is a Raleigh, North Carolina-based AI startup that focuses on analysing agricultural information derived from the pictures taken by drones and satellites. The primary focus of the company is to detect pests, diseases, and reduced plant nutrition on farms [21]. In April 2017, the firm limited the free access of its products for John Deere's customers via June 2017. With this collaboration, it is very much clear that John Deere is showing more interest in entering into agricultural tech freedom.

\section{Artificial Intelligence in Food Processing Industry}

In this section, authors are going to discuss the importance and application of different areas of artificial intelligence such as pattern recognition, data science, deep learning, machine learning, and robotics in the food processing industry. Along with food processing, the food handling 


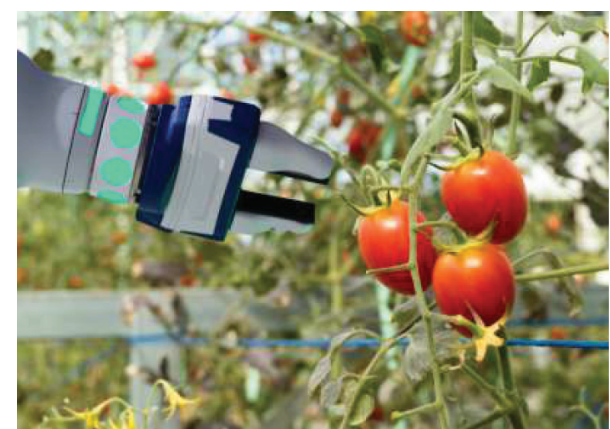

FIGURE 3: Robocrop picking fruits [20].

industry is also important where AI plays a key role in handling the entire processing unit task. There are some important applications taken from the food processing and handling industry, as shown in Figure 4.

3.1. Product Sorting and Packaging. In the food processing industry, the proper ordering and packaging of food products is one of the tedious tasks and time-taking processes for manufacturing units. Therefore, such a tedious task can be handled by AI-based systems so that the chance of error is minimized, and the production rate of the industry is rapidly increased. The development of AI-based systems is a challenging task due to the irregularities in shapes, colour, and sizes of vegetables and fruits. For developing an AI-based sorting and packaging system, a large amount of data is needed so that the system is properly trained and performs the task in an efficient manner $[26,27]$. Various research groups designed different systems for the same task. One of them is TOMRA, which performs the sorting task in a very efficient manner. It improved the production rapidly with the accuracy of $90 \%$. In current situations, most of the product sorting and packaging tasks are performed by the automated system. By using such types of systems, industries gained some advantages such as faster production rate, high-quality yielding, and labor cost cutting. Figure 4 shows important applications taken from the food processing and handling industry.

The AI-based intelligent decision-making systems consist of various tools and methodologies, i.e., high-resolution cameras, laser-technology-based systems, X-ray-based systems, and IR spectroscopy. These tools and technologies are used to analyze each and every aspect of the food products such as fruits and vegetables at the input channel. Conventional systems are only able to characterize good and bad products according to their appearance. By using TOMRA, it has been observed that the detaching and ordering problem can be improved by $5-10 \%$ in the case of potatoes only $[28,29]$. The same type of problem was also handled by a Japanese company that uses a TensorFlow ML-based system and also achieved a remarkable outcome and gained significant benefit in their assembling unit. This system achieved remarkable results for other food processing industries also. In addition, each organization found that the AI-based system works more precisely. The performance achieved for potatoes encourages the expansion of AI-based

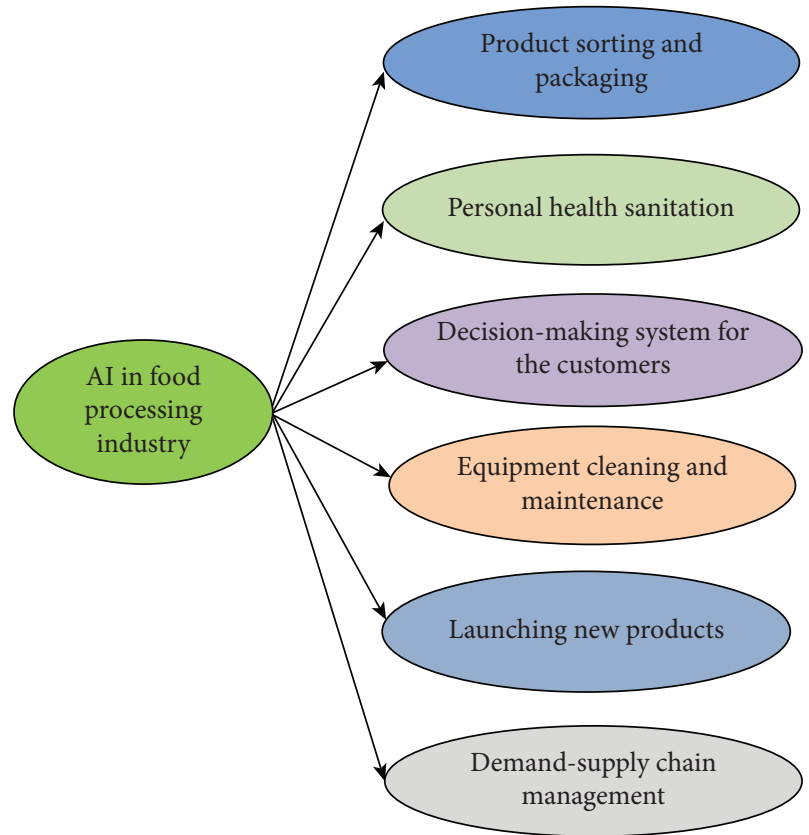

FIGURE 4: Important applications taken from food processing and handling industry.

systems for others also. It can be further expanded for different sections or departments of the food processing industry.

3.2. Personal Health Sanitation. In the literature, it has been also found that different countries across the globe such as the USA launched the food processing unit sanitation guideline. Such guidelines have also been taken care of by the AI-based systems. Initially, the KanKan and Shanghai municipal health agency worked together to develop an AIbased system. The first AI-based system is designed to grant object and facial recognition for an anonymous quantity. The system is used to monitor individuals who are not following the guidelines [30]. If anything matches, then it can be resolved in real time without any delay. The designed system shows very good results; therefore, it has been planned to expand the system for more and more organizations.

3.3. Decision-Making System for Customers. In different organizations, it is found that AI is not only helping food processing industries in developing various flavor amalgamation but also assisting the customers in picking innovative essences [31]. In 2018, Kellog launched BearNaked-Custom that is most favorable for the customers to make their adapted granola from more than 50 constituents. With taking care of every individual, it records their flavors, customer taste selection, and much more information. Such type of information is playing an important role for launching a new product into the market [31,32]. Therefore, AI again played a good role in developing decision-making systems for customers. 
3.4. Equipment Cleaning and Maintenance. In food processing industries, proper cleaning and maintenance of processing tools are very much essential. Such a task can be easily handled by AI-based systems [33]. For implementing this, various sensors and cameras are deployed to perform the task. One product of Whitwell and Martec muscularly suffers that it can decrease to only $50 \%$, which permits large efficiency and a lesser amount of time. Presently, Martec is trying to justify its AI-based cleaning place model. For this approach, Martec employs ultrasonic sensing imaging methods and optical fluorescence methods to cultivate the obtained information to the AI system development [34]. It measures the remaining amount of food and microbial debris inside the machine. After releasing the entire report of the testing phase, the system will take stand.

3.5. Launching New Products. The launching of new products for any production unit is a tedious task. Especially, in the case of food industries, it totally depends on the consumer's interests. Therefore, the information collected by the various decision-making systems for customers is helpful for the launching of new products. The collected information is processed by the ML-based module and then takes the proper decision for the product $[2,35]$. By using an MLbased approach, questions such as "what customers are exactly looking out for" has been answered. Presently, nearly all the food processing industries and food product packaging industries are utilizing the power of artificial intelligence to expand and launch new products into the market. Previously, this work has been carried out through a case study or survey. Therefore, the success rate for the system is very low. Now, the entire scenario is changed, and AI and ML are prominently used for such types of tasks.

In the entire region of the USA, a self-service soft drink corner has been installed by Coca-Cola. By using this, customers have the option to make thousands of drinks by adding minor variations in flavors. Such type of activity has been recorded by the machine, and the rest of the analysis is performed by the ML and deep learning algorithms. By using these data, new products can be launched. Cherry sprite is the real time example of a product. It has been also suggested that, in the next coming decades, most of the food industries will take advantage of the recommendation system for developing new products.

3.6. Demand-Supply Chain Management. As long as food industries are more worried about food safety policies, they are required to materialize more translucently regarding the pathway of food products in the supply chain system. To monitor every stage of the process AI is deployed [1]. It manages everything such as price control to inventory management. It also takes care of forecasting and monitoring the pathway of possessions from where they are grown to the location where customers collect it. AI-based Symphony Retail provides the facility to book transportation, billing, and inventory management [36]. It also maintains the discipline and avoids getting plenty of commodities that end up in exhausted material.

\section{Data Analysis at Food Industry}

The food-based industry is stuffed with a large number of well-established brands as well as food outlets. Due to the growing competition, this industry is losing its attraction for establishing a new business [37]. In the food industry, using technology, especially data science, is the only way which can make anyone stay upfront in the competition. Figure 5 gives the information regarding data analysis in the food industry.

4.1. Customer Satisfaction. Ooshma Garg, the founding father of Gobble, shared a thought that a food industry can be phrased as a tech company. It was a disputable assertion for the rest of the world, but there's some truth behind this $[37,38]$. Data science has become a prerequisite in current technology-driven industries for elevating and maneuvering their diverse business practices. Gobble is a great example industry which completely relies on data science for predicting the supplies as well as the demand of its customers. It offers its customers with ten-minute dinner kits and has more than thousands of regular customers with different menu choices. It collects the data such as buying history, customer behavior, and feedback and food preference of different time frames to ensure the readiness to meet the demands [39]. Gobble is a demand-driven example of a company that utilizes the artificial intelligence within the food industry and can surely serve as a blueprint for other businesses in their domain.

4.2. Introducing New Recipes. A single recipe can be cooked in numerous ways by combining the ingredients. In addition, the fact is that those ingredients can be cooked in some other ways which creates an area of endless possibilities to make cooking dishes. On the web, multiple recipes are available online and contain a huge dataset that allows the exploration of components in several cuisines from common man to professionals. The researchers can determine the differences as well as the similarities between the different cuisines [40]. For example, North American and Western European cuisines are totally based on the ingredients which contain the same flavor of compounds that East-Asian and Southern-European cuisines avoid.

In conclusion, the technologists can appraise which food components have a decent savor and mark a cuisine that is trendy in a few provinces. This basic understanding also permits artificial-intelligence-based algorithms to recommend the chefs with different types of ingredient combinations that will surely result in broadening the menu as well as the profits of a food industry.

4.3. Reinventing Food Delivery. Online food outlets such as for Swiggy, Zomato, and Uber-eat have a large amount of data based on ordering patterns of their customers and dish preferences. Data science and AI can be utilized by the foodbased professional for creating simpler, cost-effective, and time-efficient methods for delivering the product [41]. AI is beneficiating some existing industries with some valid chances for market domination. But still, it is nascent in the 


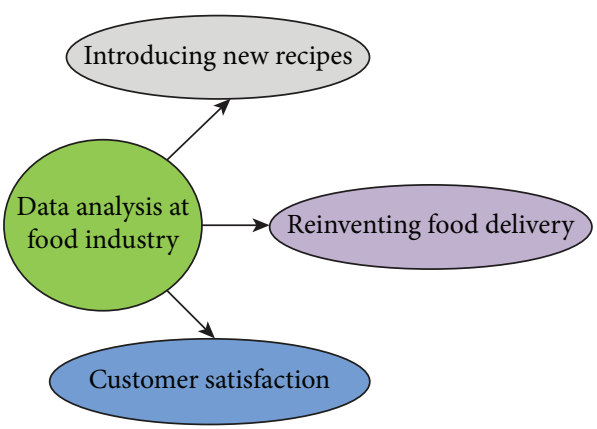

Figure 5: Data analysis at food industry.

food industry and, therefore, needs more proficient optimization by food companies as well so people can get their food with better services.

\section{Application of ML in the Restaurant Business}

The application of ML and AI techniques is not limited to only making the automated system, robocrops, soil monitoring, and new product launching. It can be also useful in the restaurant business for many numbers of services $[42,43]$. The list of applications of ML in restaurant business is given in Figure 6.

5.1. AI-Based Customer Feedback System. Nowadays, there are many kinds of applications within the domain of food services which help in predicting the number and type of food being ordered as well as the relevant inventories. This information can be utilized for statistical analysis of visitor traffic and food items that would be needed during a period of time [43]. Such information is collected by combining the data of previous engagements with the customers, their food preferences, habits, and complaints, as well as supply of the required items during that period. The result of collecting and analysing the information helps the food-service-based applications to secure more food orders from old as well as new customers, thus securing the consumer loyalty. Moreover, it also helps in removing the loopholes and complaints that make these applications more fail-safe and reliable [44]. There are some other applications which assist with the functionalities of the food-service-based applications such as the restaurant management framework, payment gateway applications, cloud-based big-data applications, and even the restaurant table booking platforms.

5.2. Food-Vending Terminals and Applications. It has become the need of a food-selling firm to build a reliable system for providing its services online to the people after it decides its menu and marketing strategy. This system can be an online site that can provide the benefit of fast ordering and recommendations or a mobile application that comes with added advantages such as incorporating an artificialintelligence- (AI-) based system. Due to the emerging foodbased e-commerce applications, it is a wise decision to enlist one's food-selling firm to their repository [44]. It allows the firm to have best functionalities of these e-commerce

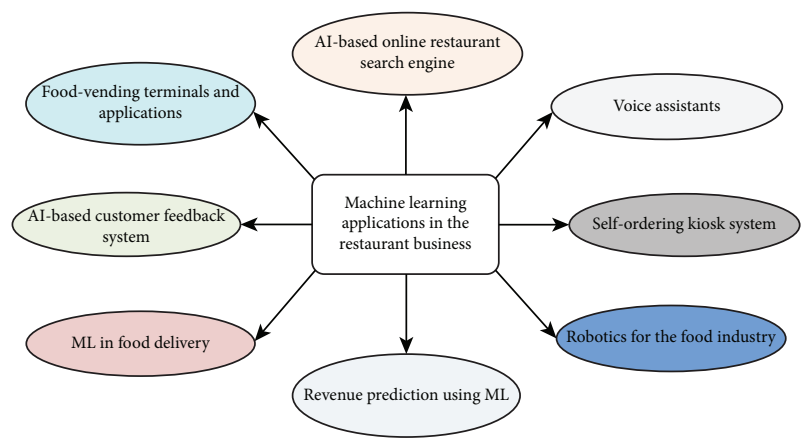

FIgURE 6: ML application in the restaurant business.

applications without spending more money in developing the same for itself, although the amount of commission charged by the e-commerce can still lead the firm to develop it. AI can help in developing an automated customer-service segment that enables the firm to efficiently perform administrative tasks such as consumer grievance redressal, dispatching crews, and creating reports.

5.3. AI-Based Online Restaurant Search Engine. It is observed that consumers often prefer a cafe, bar, or restaurant by comparing its ratings with competitors. Thus, it becomes important for an organization dealing in the food and beverage industry to know about the experience, either good or bad, from its customers to attract new customers or to avoid losing the old ones. These days, a large majority of customers are introduced to a food place via Google searches or another online medium. This fact is being utilized while recommending a customer with a preferred restaurant or cafe based on their locations and ratings with the help of AI [45]. These AI agents also help in notifying the customers about the offers, events, or sales in their favorite food places.

5.4. Voice Assistants. It is estimated that about $27 \%$ people preferred voice searching over conventional searching by typing. Due to this fact, the option of voice-based searching is being introduced into every food or other e-commerce industry, while an entirely new area of voice commerce such as Alexa by Amazon has been developed. This feature can now be utilized by the restaurants to enable these voice commerce applications to make quick orders from them even without looking into details, and this is helpful for new restaurants [46].

5.5. Self-Ordering Kiosk System. The point-of-sale systems (or self-service systems) are popular among the customers, especially in well-established restaurants. These systems assist the customers with the ordering process by giving them detailed information about the flavors or spices used, their preferences, and even the newly added items. These systems are now being adopted by every restaurant which incorporates automated systems. This technology has helped the restaurants in dealing with problems such as manpower shortages, customer engagements, and inaccurate orders. 
5.6. Robotics for the Food Industry. With the advancements of $\mathrm{AI}$, it has become possible to utilize the efficiency of robotics in the food-based industries, although it has not been adopted on a large scale yet. There are a wide range of robotics that are being used in various areas of the food industry such as drones in food delivery and robotic arm on processing the food $[18,19]$. However, as the cost of introducing these technologies in the food-based industry is higher than employing the manpower, these technologies are not being adopted. Some recent innovations in robotics are delivery drones and bots being used by "7-Eleven" convenience stores, "Flippy": a two-arm robot for frying and packing the burger patties.

5.7. Revenue Prediction Using ML. For a running business such as a restaurant and food outlet, the quality of food and services given by the owners is very important. Apart from the service and food, the prediction of sales output of the restaurant is also an essential part of the business. The owner of the food chains or restaurants needs to compile a strong business plan for their future operations for better business growth and more profit. In artificial intelligence, multiple fitting algorithms can be used to create a sales forecast [47]. In the food industry, finding a suitable fitting algorithm for the sales prediction, i.e., for five months' sales prediction or 14 months' sale prediction, requires a huge time and seamless efforts. In this era of data science, it is possible to get sales predictions on fingertips. Data science allows finding the best suitable algorithm for a particular business and easy deployment of the algorithm in the same business with a perfect AI development team.

5.8. ML in Food Delivery. Machine Learning (ML) can help in efficiently solving the problems such as deciding the delivery routes, supply of raw materials, predicting the demands of certain food items, and planning the logistics [48]. The delivery route problems can be solved with ML by optimizing the location of the delivery agent with current or upcoming traffic situations and then notifying them about the best route in a synchronous manner. By ensuring the efficient and timely delivery, it becomes easier to provide constant orders and to even deal with problems such as running out of delivery agents or late deliveries. Moreover, by incorporating the ML, the scale of collected data increases with time which can later be analyzed using other artificialintelligence-based algorithms for developing a more intelligent system. Such analysis could be performed using more advanced AI-based techniques such as deep learning (DL) that provide an added advantage over the competitors.

\section{Artificial Intelligence in Food Safety}

Due to the sterile nature of robots, it is widely acceptable in food processing industries. This feature is a huge factor in decreasing the number of foodstuff-related diseases. The Food Safety Modernization Act (FSMA) has drafted stricter hygienic necessities, which is applicable for complete supply chain systems. The cause behind it is cereals, spices, and other food products that do not need refrigerators and they are in the most prone area of contamination. Formerly, such food products were free from contamination, but now, the scenario is entirely changed. For these types of problems, AIbased systems can surely help to resolve the problem. They are free from transferring illnesses as a human can do. However, the maintenance of an AI-based system is simple and easy $[2,49]$. According to the report published by Technavio, the implementation of robots in food processing industries will lift up by $30 \%$ and also fulfill the government's demands. There are also some new revolutionary inventions by using artificial intelligence in food safety approaches that are anticipated to become well-known soon. They have the major objective to plummeting the frequency of food-borne diseases. Figure 7 shows artificial intelligence in food safety.

6.1. Next-Generation Sequencing and Electric Noses. The two most promising inventions in the food industry are nextgeneration sequencing (NGS) and electric noses (ENs). NGS replaces the DNA approach in the food security region very quickly. The introduction of AI-based automated systems and workflows helped formulate data acquisition and laboratory trials much quicker and more accurately than ever. The NGS can find hazardous inclination very quickly and efficiently. It can also prevent the infection epidemics before the impairment of an ample amount of people. ENs are mainly the surrogate for a person muzzle in fabrication surroundings. Some sensors are placed that can precisely identify a diversity of smells. These sensors just sense the smell around the surroundings, and sensed data are transferred to a data center where ML algorithms access these data $[49,50]$. According to the decision made by the ML-based system, an alarm signal is transferred to the manufacturing units. Therefore, EN can be the upcoming future of food products safety.

6.2. Food Waste Management. The report published by the Department of Agriculture, USA, declares that, "In the United States, food waste is estimated at between 30 and $40 \%$ of the food supply. This estimate, based on estimates from the USDA's Economic Research Service of 31 percent food loss at the retail and consumer levels, corresponded to approximately 133 billion pounds and \$161 billion worth of food in 2010. This amount of waste has far-reaching impacts on the society."

According to McKinsey, AI can resolve such type of issues and disengage huge amount of opening by dipping food waste by the 2030. Such surprising statistics can be accomplished by launching supplementary regenerative leisure farming practices [51]. It shows that humans are not utilizing the available resources efficiently. The traditional methods of farming can be replaced by the smarter farming methods. In this, various sensors are deployed and collect the information. The collected information is processed with ML algorithms, and then appropriate decisions are taken. By using these, farmers can make decisions the fastest and accurate. Here are some suggested ways to reduce the food waste with AI: 


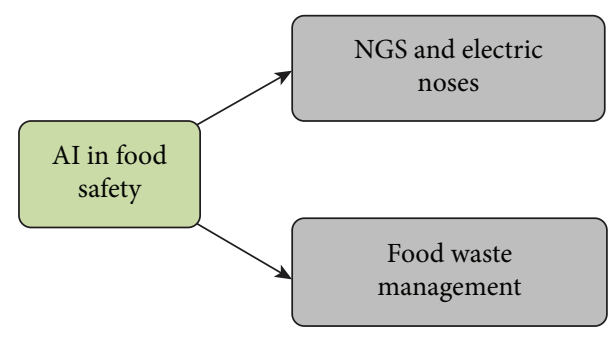

FIgURE 7: Artificial intelligence in food safety.

(i) While several elucidations examine the maturity of the fruits, others stature out what microorganisms can boost fruits and vegetables development not including the participation of artificial fertilizers.

(ii) Manufacturers can acquire purge of ground examination, gaining from compensation of the artificial intelligence that will keep a considerable amount of capital.

(iii) The farm-based food supply chain management uses computer vision technology to manage and examine each process; then, the food waste will be decreased rapidly.

(iv) Artificial-intelligence-based food tracking systems will enable us to sell food ahead of it turning into waste. By using this, more farmers and people can connect for buying the food products.

The major challenges to execute such types of ideas in reality cannot be conveyed by one organization and one body of the system. The entire food industry needs to be altered. A complete association of associates is required to work together to make an efficient system which significantly blows on the entire globe.

\section{The Remuneration of Artificial Intelligence in the Food Industry}

There are a few advantages of artificial intelligence in food industries listed as follows:

(i) In recent times, almost all food processing industries are unquestioning AI to advance the demandsupply chain management, meticulous logistics, and predictive analysis, as well as to add precision in the system.

(ii) Digitization of the demand-supply chain management systems eventually compels returns and offers a superior appreciation of the circumstances. Artificial intelligence can examine massive amounts of data that are far from human potential.

(iii) AI helps industry to diminish the time to marketplace and improve agreement with suspicions.

(iv) Automated ordering will positively decrease labor expenses, enlarge the pace of the manufacturing, and advance the excellence of products.

\section{The Future Application of AI in Food Industry}

After the investigation of the literature in the food industry, it can be observed that there is a need for a significant amount of investment in the food processing and manufacturing industry. By applying AI, systems can easily identify various issues in food production than man-based systems. It has also been noticed that researchers are prominently working on this sector. Gayama, an agrotech firm based in Switzerland, is an excellent example of one such firm that has raised a sum of $\$ 3.2$ million for an artificial-intelligence-driven project. The project is based on hyperspectral cameras that are able to distinguish a minor fluctuation in water intensities, nourishment, vermin, and crop yields. Then, the artificial intelligence process finds possible intimidation and generates alert signals to farmers so that they can plan accordingly. The artificial intelligence process will also recommend convincing measures that farmers must get to preeminent use of available resources. By using ML and deep learning methods [52, 53], Earth's surface can be also analyzed by satellite data. The main intention is to discover spaces that would use some facility from the government or its shareholders for improving the crop that can improve the outcome.

It has also been observed that the farming is immobile and old fashioned in many sections of the entire globe. It could be replaced with smart farming in the near future. AI has a possibility to implement smart farming and solve the existing crisis somehow in the coming future. Successful implementation of smart farming could enhance the yields by at least $60 \%$. ML and $\mathrm{AI}$ are promising techniques, but there will be prosperity of solutions to eradicate waste in food production industries.

For example, $77 \mathrm{Lab}$ has previously launched elegant bots that can select food stuff directly from the plant, eradicating the uselessness of manual labor. There were so many self-assisted pickers in history, but these elegant bots are using machine learning or deep learning and can decide the height of maturity of any fruit, recognize fruits from different plants in a healthier manner, and handle fruits more precisely. So, these are the future of upcoming farming or food processing industries.

\section{Conclusions}

This study presented the various facts to indicate the advantages and implementation of $\mathrm{AI}$ for the food businesses in a precise manner. In the current scenario, the food industry is utilizing the basic level of artificial intelligence. Every day the role of AI is becoming vital due to its capability to escalate hygiene, food protection, and waste management system. In the future, AI is going to transform the food processing industry because it has so much potential to generate reasonable and healthier productivity for clients and employees. The employment of AI and ML in food production and eatery businesses is already taking the 
business to a new level by minimizing human mistakes in manufacturing and to a lesser extent leftover copious product. It enables low costs for packing as well as conveyance, increment in customer pleasing, rapid services, voice searching, and more personalized orders. These business advantages can also be benefited for big food factories which will bring an obvious benefit in the long run.

\section{Data Availability}

The data used to support the findings of this study are available from the corresponding author upon request.

\section{Conflicts of Interest}

All authors have no conflicts of interest to report.

\section{Acknowledgments}

The authors are grateful to the College of Engineering and Technology, Samara University, Ethiopia, for providing financial and technical support. Furthermore, the authors are greatly indebted towards Graphic Era Hill University, DIT University, and Graphic Era Deemed University for providing necessary support to carry out this work; also, the flexibility provided by the university to researchers is highly appreciable.

\section{References}

[1] V. Kakani, V. H. Nguyen, B. P. Kumar, H. Kim, and V. R. Pasupuleti, "A critical review on computer vision and artificial intelligence in food industry," Journal of Agriculture and Food Research, vol. 2, Article ID 100033, 2020.

[2] N. N. Misra, Y. Dixit, A. Al-Mallahi, M. S. Bhullar, R. Upadhyay, and A. Martynenko, "IoT, big data and artificial intelligence in agriculture and food industry," IEEE Internet of Things Journal, vol. 1, p. 1, 2020.

[3] G. Soltani-Fesaghandis and A. Pooya, "Design of an artificial intelligence system for predicting success of new product development and selecting proper market-product strategy in the food industry," International Food and Agribusiness Management Review, vol. 21, no. 7, pp. 847-864, 2018.

[4] P. K. Donepudi, "Technology growth in shipping industry: an overview," American Journal of Trade and Policy, vol. 1, no. 3, pp. 137-142, 2014.

[5] S. Vadlamudi, "Agri-food system and artificial intelligence: reconsidering imperishability," Asian Journal of Applied Science and Engineering, vol. 7, no. 1, pp. 33-42, 2018, https://journals. abc.us.org/index.php/ajase/article/view/1192.

[6] O. Castillo and P. \&Meliif, "Automated quality control in the food industry combining artificial intelligence techniques with fractal theory," WIT Transactions on Information and Communication Technologies, vol. 10, 1970.

[7] S. Bera, "An application of operational analytics: for predicting sales revenue of restaurant," in Machine Learning Algorithms for Industrial Applications, pp. 209-235, Springer, Cham, Switzerland, 2021.

[8] N. Tyagi, R. Khan, N. Chauhan, A. Singhal, and J. Ojha, "Erickshaws management for small scale farmers using big dataApache spark," in IOP Conference Series: Materials Science and Engineering, vol. 1022, no. 1, Article ID 12023, Bandung, Indonesia, April 2021.
[9] P. Jayaraman, A. Yavari, D. Georgakopoulos, A. Morshed, and A. Zaslavsky, "Internet of things platform for smart farming: experiences and lessons learnt," Sensors, vol. 16, no. 11, p. 1884, 2016.

[10] X. Morvan, N. P. A. Saby, D. Arrouays et al., "Soil monitoring in Europe: a review of existing systems and requirements for harmonisation," Science of the Total Environment, vol. 391, no. 1, pp. 1-12, 2008.

[11] S. Wolfert, L. Ge, C. Verdouw, and M.-J. Bogaardt, "Big data in smart farming-a review," Agricultural Systems, vol. 153, pp. 69-80, 2017.

[12] S. E. Lozano-Baez, Y. Domínguez-Haydar, P. Meli, I. Meerveld, K. Vásquez Vásquez, and M. Castellini, "Key gaps in soil monitoring during forest restoration in Colombia," Restoration Ecology, vol. 29, no. 4, 2021.

[13] A. L. Yagci and M. T. Yilmaz, "Mapping and monitoring of soil moisture, evapotranspiration, and agricultural drought," Springer Remote Sensing/Photogrammetry, vol. 299, pp. 299320, 2021.

[14] A. Qin, D. Ning, Z. Liu, and A. Duan, "Analysis of the accuracy of an FDR sensor in soil moisture measurement under laboratory and field conditions," Journal of Sensors, vol. 2021, pp. 1-10, 2021.

[15] J. Palti and Y. Cohen, "Downy mildew of cucurbits (Pseudoperonospora Cubensis): the fungus and its hosts, distribution, epidemiology and control," Phytoparasitica, vol. 8, no. 2, pp. 109-147, 1980.

[16] R. Raut, H. Varma, C. Mulla, and V. R. Pawar, "Soil monitoring, fertigation, and irrigation system using IoT for agricultural application," in Intelligent Communication and Computational Technologies, pp. 67-73, Springer, Singapore, 2018.

[17] S. Bhattacharyya, P. Sarkar, S. Sarkar, A. Sinha, and S. Chanda, "Prototype model for controlling of soil moisture and ph in smart farming system," in Computational Advancement in Communication Circuits and Systems, pp. 405-411, Springer, Singapore, 2020.

[18] B. Melander, B. Lattanzi, and E. Pannacci, "Intelligent versus non-intelligent mechanical intra-row weed control in transplanted onion and cabbage," Crop Protection, vol. 72, pp. 1-8, 2015.

[19] J. Machleb, G. G. Peteinatos, B. L. Kollenda, D. Andújar, and R. Gerhards, "Sensor-based mechanical weed control: present state and prospects," Computers and Electronics in Agriculture, vol. 176, Article ID 105638, 2020.

[20] S. Imran, S. Ahmad, and D. H. Kim, "Quantum GIS based descriptive and predictive data analysis for effective planning of waste management," IEEE Access, vol. 8, pp. 46193-46205, 2020.

[21] A. Giri, D. R. R. Saxena, P. Saini, and D. S. Rawte, "Role of artificial intelligence in advancement of agriculture," International Journal of Chemical Studies, vol. 8, no. 2, pp. 375380, 2020.

[22] S. Gupta, G. Singal, and D. Garg, "Deep reinforcement learning techniques in diversified domains: a survey," $A r$ chives of Computational Methods in Engineering, vol. 10, pp. 1-40, 2021.

[23] D. Sepulveda, R. Fernandez, E. Navas, M. Armada, and P. Gonzalez-De-Santos, "Robotic aubergine harvesting using dual-arm manipulation," IEEE Access, vol. 8, pp. 121889121904, 2020.

[24] J. Gai, L. Tang, and B. L. Steward, "Automated crop plant detection based on the fusion of color and depth images for 
robotic weed control," Journal of Field Robotics, vol. 37, no. 1, pp. 35-52, 2020.

[25] S. Bucher, K. Ikeda, B. Broszus, A. Gutierrez, and A. Low, "Adaptive robotic chassis (ARC)," RoboCrop A Smart Agricultural Robot Toolset, vol. 69, 2021.

[26] S. Tripathi, S. Shukla, S. Attrey, A. Agrawal, and V. S. Bhadoria, "Smart industrial packaging and sorting system," in Strategic System Assurance and Business Analytics, pp. 245-254, Springer, Singapore, 2020.

[27] T. Dewi, P. Risma, and Y. Oktarina, "Fruit sorting robot based on color and size for an agricultural product packaging system," Bulletin of Electrical Engineering and Informatics, vol. 9, no. 4, pp. 1438-1445, 2020.

[28] M. O. Onishchuk, "Opto-mechanical sorting of municipal solid waste," vol. 46, pp. 514-588, BНTУ, Vinnytsia, Ukraine, 2020, Doctoral dissertation.

[29] L. Bünger, "Robotic waste sorting," Worcester Polytechnic Institute, Worcester, MA, USA, 2021, http://www.wpi.edu/ Academics/Projects Doctoral dissertation.

[30] E. Rary, S. M. Anderson, B. D. Philbrick, T. Suresh, and J. Burton, "Smart sanitation-biosensors as a public health tool in sanitation infrastructure," International Journal of Environmental Research and Public Health, vol. 17, no. 14, p. 5146, 2020.

[31] S. Dehghan-Dehnavi, M. Fotuhi-Firuzabad, M. MoeiniAghtaie, P. Dehghanian, and F. Wang, "Estimating participation abilities of industrial customers in demand response programs: a two-level decision-making tree analysis," in 2020 IEEE/IAS 56th Industrial and Commercial Power Systems Technical Conference (IఓCPS), pp. 1-8, IEEE, Las Vegas, NV, USA, June 2020.

[32] E. Yost and Y. Cheng, "Customers' risk perception and dineout motivation during a pandemic: insight for the restaurant industry," International Journal of Hospitality Management, vol. 95, Article ID 102889, 2021.

[33] X. Wang, V. M. Puri, and A. Demirci, "Equipment cleaning, sanitation, and maintenance," in Food Safety Engineering, pp. 333-353, Springer, Cham, Switzerland, 2020.

[34] R. H. Schmidt and H. M. Piotter, "The hygienic/sanitary design of food and beverage processing equipment," Food Safety Engineering, Springer, Cham, Switzerland, pp. 267-332, 2020.

[35] S. Wardah, T. Djatna, M. Marimin, and M. Yani, "New product development in coconut-based agro-industry: current research progress and challenges," in IOP Conference Series: Earth and Environmental Science, vol. 472, no. 1, Article ID 12053, Changchun, China, August 2020.

[36] S. S. Bhattacharyya, D. Maitra, and S. Deb, "Study of adoption and absorption of emerging technologies for smart supply chain management," International Journal of Applied Logistics, vol. 11, no. 2, pp. 14-54, 2021.

[37] D. Tao, P. Yang, and H. Feng, "Utilization of text mining as a big data analysis tool for food science and nutrition," Comprehensive Reviews in Food Science and Food Safety, vol. 19, no. 2, pp. 875-894, 2020.

[38] E. Fainshtein, E. Serova, and P. Vorobyev, "Contemporary research and analysis of food industry: case of Russian restaurant business network branch," in Eurasian Business Perspectives: Proceedings of the 29th Eurasia Business and Economics Society Conference, pp. 183-199, Springer International Publishing, Lisbon, Portugal, April 2021.

[39] S. A. Topleva and T. V. Prokopov, "Integrated business model for sustainability of small and medium-sized enterprises in the food industry," British Food Journal, vol. 122, no. 5, pp. 1463-1483, 2020.
[40] I. I. Ageikina, E. G. Lazareva, I. Y. Mikhailova, and V. K. Semipyatny, "Results designing and analysis when introducing new beverage identification criteria," Food Systems, vol. 3, no. 3, pp. 4-7, 2020.

[41] J. J. Kim, I. Kim, and J. Hwang, "A change of perceived innovativeness for contactless food delivery services using drones after the outbreak of COVID-19," International Journal of Hospitality Management, vol. 93, Article ID 102758, 2021.

[42] S. Bera, "An application of operational analytics: for predicting sales revenue of restaurant," in Machine Learning Algorithms for Industrial Applications. Studies in Computational Intelligence, S. Das, S. Das, N. Dey, and AE. Hassanien, Eds., vol. 907, pp. 209-235, Springer, Cham, Switzerland, 2021.

[43] P. Ponnusamy, A. Roshan Ghias, C. Guo, and R. Sarikaya, "Feedback-based self-learning in large-scale conversational ai agents," in Proceedings of the AAAI Conference on Artificial Intelligence, vol. 34, no. 08, pp. 13180-13187, New York, NY, USA, February 2020.

[44] M. Stone, E. Aravopoulou, Y. Ekinci et al., "Artificial intelligence (AI) in strategic marketing decision-making: a research agenda," The Bottom Line, vol. 33, no. 2, pp. 183-200, 2020.

[45] K. Blöcher and R. Alt, "AI and robotics in the European restaurant sector: assessing potentials for process innovation in a high-contact service industry," Electronic Markets, vol. 2, 2020.

[46] X. Y. Leung and H. Wen, "Chatbot usage in restaurant takeout orders: a comparison study of three ordering methods," Journal of Hospitality and Tourism Management, vol. 45, pp. 377-386, 2020.

[47] G. P. Sanjana Rao, K. Aditya Shastry, S. R. Sathyashree, and S. Sahu, "Machine learning based restaurant revenue prediction," in Evolutionary Computing and Mobile Sustainable Networks, pp. 363-371, Springer, Singapore, 2021.

[48] M. Keeble, J. Adams, G. Sacks et al., "Use of online food delivery services to order food prepared away-from-home and associated sociodemographic characteristics: a cross-sectional, multi-country analysis," International Journal of Environmental Research and Public Health, vol. 17, no. 14, p. 5190, 2020.

[49] E. Fedorova, V. Darbasov, and M. Okhlopkov, "The role of agricultural economists in study on problems related to regional food safety," in E3S Web of Conferences, vol. 176, p. 5011, October 2020.

[50] X. Yu, Y. Lin, and H. Wu, "Targeted next-generation sequencing identifies separate causes of hearing loss in one deaf family and variable clinical manifestations for the p.R161C Mutation in SOX10," Neural Plasticity, vol. 2020, pp. 1-8, 2020.

[51] V. Filimonau, E. Todorova, A. Mzembe, L. Sauer, and A. Yankholmes, "A comparative study of food waste management in full service restaurants of the United Kingdom and The Netherlands," Journal of Cleaner Production, vol. 258, Article ID 120775, 2020.

[52] C. Bhatt, I. Kumar, V. Vijayakumar, K. U. Singh, and A. Kumar, "The state of the art of deep learning models in medical science and their challenges," Multimedia Systems, vol. 12, 2020.

[53] T. K. Sharma and A. Abraham, "Artificial bee colony with enhanced food locations for solving mechanical engineering design problems," Journal of Ambient Intelligence and $\mathrm{Hu}$ manized Computing, vol. 11, no. 1, pp. 267-290, 2020. 